\title{
The displacements and deformations of electric sparks by Electrostatic Actions
}

\section{Aug. Righi}

To cite this article: Aug. Righi (1883) The displacements and deformations of electric sparks by Electrostatic Actions, Philosophical Magazine Series 5, 15:91, 72-72, DOI: $10.1080 / 14786448308627313$

To link to this article: http://dx.doi.org/10.1080/14786448308627313

册 Published online: 28 Apr 2009.

Submit your article to this journal $[\pi$

Џll Article views: 2

Q View related articles $\widetilde{ }$ 


\section{THE DISPLACEMENTS AND DEFORMATIONS OF ELECTRIC SPARKS} BY FLECTROSTATIC ACTIONS. BY AUG. RIGHI.

Known experiments show that the electric discharge commences when the electric density on the electrodes has attained a sufficient value relatively to the dimensions of the balls, their quality, distance, \&c.* Supposing that the discharge is constituted by the emission of electrified particles, it will commence at that one of the two electrodes on which the density is the greater-from which we derive the explanation of many phenomena.

If, then, at but little distance from the place where the spark is formed there are other electrified bodies, the particles will deviate from their path, moving away from the bodies which have charges of the same name as that of the electrode which repels them, and approaching the bodies charged with the contrary electricity.

Now the spark must pursue the path of the first particles repelled ; for, by reason of the heat evolved, it offers less resistance. Therefore the spark itself will deviate, as if it were a body charged with electricity of the same sign as that of the electrode on which the density previous to the discharge is the greater.

The following is one of the ways in which I have verified this class of facts:- The two stems bearing the discharge-balls are arranged vertically one below the other, and at equal distance two parallel vertical disks are kept constantly charged, the one with pusitive, the other with negative electricity, by a Holtz machine with auxiliary combs, the exciters of which are sufficiently distant from one another for the sparks not to explode. It is readily observed that, when the two disks are not charged, the form of the spark produced between the two stems by the discharge of a condenser charged by another Holtz machine is nearly a straight line (if the distance between the balls is not too great); but if the disks are charged and if the two balls are not in all respects identical, the spark is curved, approaching the one or the other disk. The changes of shape are very remarkable when a liquid resistance such that the spark becomes yellow is inserted in the discharge-circuit. The spark then takes very eurious forms; and at the same time it is observed to start from points of the electrodes situated laterally.

Suppose, for example, that the two balls are identical in dimensions and quality, but that one of them, the negative, communicates with the earth; the greater density is then on the positive ball, and it is there that the discharge will commence. The spark, in fact, is displaced and deformed as a positively electrified flexible body would be. The same effect is obtained if, both balls being insulated, the diameter of the negative is greater than that of the positive ball.-Comptes Rendus de l'Académie des Sciences, Dec. 11, 1882, t. xcv. p. 1223-24.

* A. Righi, "Sulle scariche elettriche," Nuovo Cimento, ser. 2, xvi, pp. $89 \& 97$. 